\title{
O DiÁRIO DE DANIEL: ALGUMAS REFLEXÕES SOBRE A AQUISIÇÃO
}

DE SUA LÍNGUA MA-PAI-TERNA

SiLVIA LuCIA BIGONJAL BRAGGIO*

\section{Resumo}

O processo de aquisição de língua pela criança tem sido tratado sob várias abordagens, desde que a psicolingüística se constituiu como área de estudo da lingüística. Neste artigo, trato do processo de aquisição de língua de uma criança no período de 1 ano e três meses a 1 ano e seis meses, dezembro de 2006 a fevereiro de 2007. Nele, descrevo e teço algumas reflexões sobre os seus primeiros sons significativos, coletados em eventos de fala em seu cotidiano, que revelam a intrínseca relação entre a fonética/fonologia e a construção do significado. Assim a fonologia métrica é o principal suporte teórico deste trabalho na análise dos dados, pois permite considerar a minha hipótese de que a sílaba e seu ápice (acento) são fatores essenciais na percepção da criança em seus primeiros passos em direção à aquisição de sua língua.

PalaVras-Chave: psicolingüística, aquisição de língua, fonologia métrica.

\section{INTRODUÇÃO}

A aquisição de língua materna tem sido objeto de estudo de lingüistas e psicólogos cognitivistas, mesmo antes de a área de psicolingüística ter surgido mais significativamente após os primeiros trabalhos de Chomsky $(1957,1959,1965)$ dentro da perspectiva gerativista/ inatista. Esta área fascinante tem sido centrada, ora na criança (SLOBIN, 1979), ora na interação com seus interlocutores (O'GrADY et al., 1997; Hyams, 1986; Scarpa, 2001 e Braggio, 1992). No momento, ambas são factíveis para analisar e descrever esse processo de construção de uma

* Professora Titular de Lingüística da Faculdade de Letras da Universidade Federal de Goiás. E-mail: silvialbb@terra.com.br 
língua com a qual a criança interage. Neste artigo, no qual pretendo explorar algumas possibilidades do processo de aquisição, há momentos em que somente a criança é o foco do nosso olhar e, em outros, focalizo os eventos de fala dos quais ela faz parte. Além do mais, utilizo-me de outras abordagens, como a body language (os gestos, as expressões faciais e corporais), e da interação criança-objetos em seu cotidiano. Do meu ponto de vista, nenhuma dessas abordagens explica, por si só, o processo de aquisição de uma língua. Todos estão intrinsecamente relacionados e nenhum deles ocorre em um vacuum. É possível olhar, descrever e analisar um determinado aspecto em isolamento, isto é, fazer um recorte daquele aspecto como, por exemplo, do desenvolvimento da fonética/fonologia. Todavia, nenhum aspecto está separado da relação da criança com os sujeitos/objetos, da importante ação de apontar e reconhecer, e das expressões corporais que o acompanham no contexto situacional concreto.

Nosso sujeito, Daniel, tem um ano e meio e tem sido por mim observado desde que nasceu em 3/8/2005. Todavia, não vou me deter nos primeiros momentos de sua aquisição. Neste artigo, descrevo e reflito sobre os dados observados, coletados, gravados e filmados por mim e por seus pais nos últimos três meses, que vão de dezembro de 2006 a fins de fevereiro de 2007, quando Daniel tinha entre 1 ano e 4 meses e 1 ano e 6 meses. Todos os dados foram coletados naturalisticamente, extraídos de eventos de fala, ou de eventos de comunicação reais, em pesquisa qualitativa (AgAR, 1983; Hymes, 1967, 1974). Neste artigo, a fonologia métrica (GoldsMith, 1990) dá suporte à análise dos dados, mas outras abordagens estão presentes nos contextos em que os dados lingüísticos de fato acontecem. A partir deles, pretendo refletir e lançar alguma luz sobre esse processo que, além de fascinante, é bastante complexo para quem o estuda com a convicção de que, na construção de sua língua, a criança pode nos dar subsídios para entendê-la a partir de sua gênese. 
Não é meu objetivo descrever cada uma das teorias de aquisição de língua. Vou apenas apontá-las neste estudo. No início da década de 1950, teve grande impacto, principalmente nos Estados Unidos e na Inglaterra, a teoria behaviorista, ligada às concepções da psicologia behaviorista de Skinner (1957) e antecessores. Seu principal representante nos EUA, na lingüística, Bloomfield (1933), foi fortemente influenciado pela idéia behaviorista de que a aquisição de uma língua se dá através da associação entre estímulos e respostas com base somente na experiência, uma concepção empirista sobre a aquisição do conhecimento. Esta concepção deu origem à hipótese da privação que considera que, sem estímulos "adequados" em seu ambiente, a criança teria um código restrito, ou uma língua limitada, isto é, menos elaborado (código elaborado) do que a que tivesse estímulos adequados (BERNSTEIN, 1972). Obviamente, em uma sociedade com diferenças de classe e de etnia, as crianças das classes trabalhadoras e de etnias não anglo passaram a ser altamente estigmatizadas. É nesse cenário que Chomsky (1959), em seu clássico artigo “A Review of B. F. Skinner's Verbal Behavior”, ataca duramente a visão behaviorista e lança os fundamentos da teoria inatista, racionalista, segundo a qual toda e qualquer criança nasce com uma faculdade de linguagem, ou, mais recentemente, órgão da linguagem, que a capacita a adquirir plenamente qualquer língua ou línguas, independentemente de classe ou etnia. Ou seja, toda criança nasce com os "princípios" de uma gramática universal (GU), que são aplicados à língua em aquisição ("parâmetros"), na exposição a uma determinada língua. Muitos estudos, desde então, têm sido feitos a partir desta perspectiva, constituindo mesmo uma área da lingüística, a psicolingüística (SLobIN, 1979). O foco destes estudos é a criança, ou seja, o que se descreve e analisa é a língua da criança. O papel dos interlocutores da criança nesse processo não é levado em consideração. Na Europa Ocidental, a psicologia cognitiva avança com a teoria cognitiva representada por Piaget (1978), que assume que a linguagem é vinculada a 
um processo mais amplo de cognição, não sendo a língua o foco de análise de seus estudos, mas a estruturação cognitiva e seu desenvolvimento. Por sua vez, ignorado no mundo ocidental, na União Soviética, em um cenário fortemente relacionado ao papel do social em qualquer atividade humana, Vygotsky (1962), em contraposição a Piaget, atribui um valor social intrínseco à aquisição e desenvolvimento da linguagem na criança, colocando em foco de análise tanto a criança quanto o(s) interlocutor(es) com os quais ela interage, ou seja, a teoria interacionista de aquisição da linguagem. No Brasil, Cláudia Lemos, referência essencial para quem se dedica aos estudos de aquisição de linguagem, é quem, em Sobre aquisição da linguagem e seu dilema (pecado) original (1982) e muitos outros artigos, indo bastante além do pensamento original de Vygotsky, ilumina o caminho fascinante dessa área, ao tomar o diálogo como foco de análise, por ser estruturador e estruturante no processo de aquisição. Scarpa (1984), Galves (1995), Perroni (1994), entre outros autores, vêm dando uma contribuição significativa para essa área da lingüística. O trabalho de Scarpa (GEBARA, 1984) sobre o desenvolvimento da entoação com duas crianças em processo de aquisição de suas línguas dá suporte ao meu trabalho. Nele, fui atraída pela prosódia. Por outro lado, quando se fala em uso da linguagem, não posso deixar de considerar a competência comunicativa (HyMEs, 1967) e a competência funcional (HALLIDAY, 1969), embora o termo competência seja passível de uma revisita pelos lingüistas.

A partir da observação da importância da prosódia no processo de aquisição de sua língua por Daniel, parto do que "os dados me falam" nesse momento de análise e, naturalmente, apóio-me na fonologia nãolinear, a fim de começar a desvelar os seus primeiros sons significativos. A diferença fundamental entre a fonologia linear e a não-linear é a de que aquela toma os sons e fonemas como seu foco primário de análise em uma linha não hierárquica, enquanto esta tem seu foco na "proeminência relativa", definida através de uma hierarquia dos constituintes de uma palavra ou frase e do "ritmo lingüístico", classificada através de 
uma grade métrica que possibilita que o acento "stress" seja visto dentro do núcleo de uma sílaba (único constituinte obrigatório desta). Cada segmento vocálico em uma palavra forma um núcleo silábico. Em sua forma estrutural, inicialmente coloca-se o símbolo (ó) para indicar sílaba, seguido, então, da "rima" (R), portadora do núcleo com o símbolo (N). Circundando o núcleo estão à esquerda os "onsets" (ou ataques) e, à direita, a "coda", formando, portanto, uma série de "tiers" (ou camadas) em uma forma naturalmente hierárquica com sílabas "leves" e "pesadas". Uma sílaba com coda consonantal é chamada "fechada". O stress é percebido como a proeminência de um ou mais segmentos silábicos sobre outros em uma palavra. Os traços distintivos (primeiramente concebidos por Jakobson (1972) e, em seguida, por Chomsky e Halle (1968) dentro das teorias lineares) também em uma "feature hierarchy" (hierarquia de traços), podem fazer parte desta notação e, normalmente, são auxiliares importantíssimos na resolução de modo e ponto de articulação dos sons e na explicação fonotática. São também muito úteis na definição das "classes naturais" de uma língua e das possíveis combinações entre os diferentes sons ou fonemas de uma língua, ou seja, das possibilidades dos seus padrões fonológicos, ou de suas impossibilidades. As notações estruturais são mostradas a cada exemplo coletado da fala de Daniel. É importante observar que o código musical utiliza basicamente esta concepção (NETROVsKi, 2000). A seguir, apresento a análise dos dados.

ANÁLISE DOS DADOS

A importância das propriedades suprasegmentais e da linguagem corporal

Uma das primeiras coisas que me chamou a atenção em Daniel foi que, mesmo antes de enunciar seus primeiros sons significativos, ele foi atraído irresistivelmente pela música. Ainda sentado em seu berço, no 
chão ou no colo de seus pais, antes mesmo de engatinhar, ao ouvir o som de uma música, ele balançava seu corpinho, principalmente a cabeça, sorrindo, seguindo o ritmo da música. Esse fato, óbvio, levou-me a considerar que este ritmo trazia a ele uma sensação de bem-estar que ele transmitia através da linguagem corporal (CRYSTAL, 1997), ou seja, uma manifestação ainda não-verbal que podia ser entendida por seus pais. Também foi sempre ao ritmo de uma música suave que, desde bebezinho, ele dormia ouvindo-a em CD, cantada por sua mãe ou por seu pai, enquanto era embalado. A música também tinha o poder de acalmá-lo quando ficava inquieto, choroso. Essa integração com a música, com diferentes ritmos, timbres e tons, fez-me levantar uma questão que parece bastante significativa: qual o papel da prosódia de uma língua no processo de sua aquisição pela criança, já que o efeito que ela provoca seria "mais audível" à criança, que se sente bem, confortada, segura ao ouvi-la, colada ao corpo da mãe e ao do pai? No caso de Daniel (infelizmente não no caso de todas as crianças), ela foi "falada" e "cantada" antes mesmo de nascer. Seria a prosódia, em todos os seus desdobramentos, mais saliente à percepção acústica do bebê nesta fase em que começa a compreender o significado de sua língua ma-pai-terna?

Meu olhar, naturalmente, recaiu sobre essa questão na tentativa de verificar se essas propriedades, presentes em qualquer língua natural, teriam relevância nos próximos passos de Daniel em direção à fala.

Para tanto, fui observando curiosamente os primeiros sons significativos em seu léxico. As reflexões são apresentadas no próximo item.

Não há fones isolados nesta época da aquisição

Passada a época do choro inicial, que no início é considerado pelos pais como uma incógnita, a criança gradualmente vai mostrando indícios, sinais, pistas (GYNZBURG, 1990) que passam a ser interpretáveis do porquê de seu choro: se de fome, se de sede, se de dor, se de frio, se quer colo etc. Por exemplo, se ela chora e não está com febre e, alimentada, pára de chorar, descarta-se a hipótese de uma doença; se mesmo 
alimentada continua a chorar, ou se rejeita o alimento, recorre-se a outras possibilidades. Também passada a fase do balbucio, no qual aparecem os mais diversos fones, observei que, em momento algum, fones/sons isolados são usados significativamente na fala de Daniel, ou seja, no processo da aquisição, consoantes só aparecem com vogais ou semivogais $(\mathrm{CV} / \mathrm{CSV})^{1}$ e uma vogal é sempre seguida por uma semivogal (VSV) formando um segmento único, "um vocábulo fonológico" significativo. Portanto, focalizando esse aspecto, o primeiro segmento a ser analisado é a sílaba. Mas não a sílaba por si só. Como pude verificar, a entoação teve um papel determinante na aquisição de sua língua. Quando começa a falar, Daniel segmenta a sua língua apoiado na entoação, a fim de "dizer algo para alguém" (HallidAy, 1969, Hymes, 1967), de modo a fazer sentido para o outro. Em decorrência dessa afirmação, inicio minha análise com uma teoria dentro da fonologia não-linear - a fonologia métrica - que toma a sílaba como seu foco de estudo e, conseqüentemente, o acento natural da língua, ao invés de me deter na análise de segmentos isolados de forma linear. Estes aparecerão na medida em que forem necessários para explicações de seu surgimento nas sílabas, principalmente na fonotática. Também procuro explicar as interfaces entre a fonética/fonologia, a semântica, e a body language (o corpo que fala) e a interconexão que a criança faz desses aspectos, no uso real de sua língua, nos diferentes contextos situacionais.

\section{Os primeiros sons significativos de Daniel}

É óbvio que, se a criança não interagir com outros falantes, ela dificilmente desenvolverá a "faculdade de linguagem" (Сномsку, 1957, 1965, 1981), herdada ontogenética e filogeneticamente. Assim, acredito que o ser humano possui uma faculdade de linguagem, com princípios e parâmetros que são ativados no processo da aquisição de sua língua, na interação com os falantes que fazem parte do seu cotidiano, principalmente seus pais, mas não exclusivamente estes, também com os objetos, os animais que o circundam, e as expressões corporais; em síntese, em 
um cenário repleto de vida: sons, cores, formas, odores, texturas, gostos, gestos, sensações etc. É nesse cenário que Daniel vai falar, cantar, brincar, brigar, rezar, sonhar, pedir, amar etc., usando sua língua. É nesse cenário que ele vai passar de "interpretado" a "interpretante" (LEMOS, 1984).

Como em muitas outras culturas e etnias, as primeiras palavras referem-se à mãe e ao pai. A primeira palavra enunciada por Daniel foi "mãe", referindo-se tanto à mãe quanto ao pai. Esse exemplo deu-se quando tinha 1 ano e 1 mês, em setembro de 2006. As palavras entre aspas são grafadas na forma ortográfica convencional (sem preocupação com a variedade dos outros falantes neste momento). Os primeiros exemplos foram destacados de eventos de fala e aparecem em ordem cronológica. Alguns destes eventos são descritos na íntegra. Vamos aos exemplos:

a) Estrutura 1

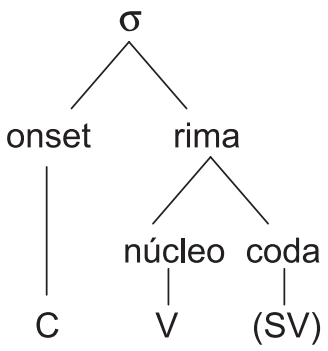

\section{(i) Padrão CVSV}
1. "mamãe"
['m
วิ
y]
$\mathrm{C}$
V
SV

A entoação é distintiva, marcadora de significado. Ela foi adquirindo contornos entoacionais nas mais diversas funções e usos: reconhecer, indicar, chamar, pedir algo, reclamar etc. (HALlYDAY, 1969; Hymes, 1967). A "língua do corpo" também explicita cada um dos sentidos pretendidos. Por exemplo, antes mesmo de dizer "não" ou "sim", 
balançar a cabeça negando ou aceitando era a sua forma de se manifestar. Como já expliquei, a língua não acontece num vacuum. Além dos sinais, indícios corporais (GINZBURG, 1990), a saliência do som, o núcleo da rima da sílaba, com seu acento fonológico, aparece como fator significativo nessa fase da aquisição. As sílabas à esquerda onset e à direita coda do núcleo aparecem apagadas, exceto quando se trata da semivogal "y". Os exemplos a seguir obedecem ao mesmo padrão.

2. "mamadeira"

['de]

CV

3. "papai"

['pay]

CVSV

4. "dá"

['da]

(do verbo dar-pedindo)

\author{
CV
}

5. "bola"

['bo]

$\mathrm{CV}$

6. "pão"

['pã ]

$\mathrm{CV}$

b) Estrutura 2

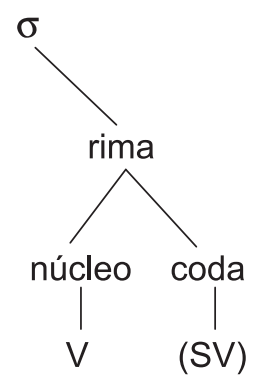

7. "ai"

['a y]

expressando ou

VSV

fingindo dor 


\section{(ii) Padrão CV-CV/V-CV}

Ao núcleo da sílaba, são adicionados um onset à esquerda ou uma coda à direita. Estou interpretando que palavras com três sílabas as têm apagadas quando o acento incide na segunda sílaba ou recebem um tratamento de reduplicação.

c) Estrutura 3
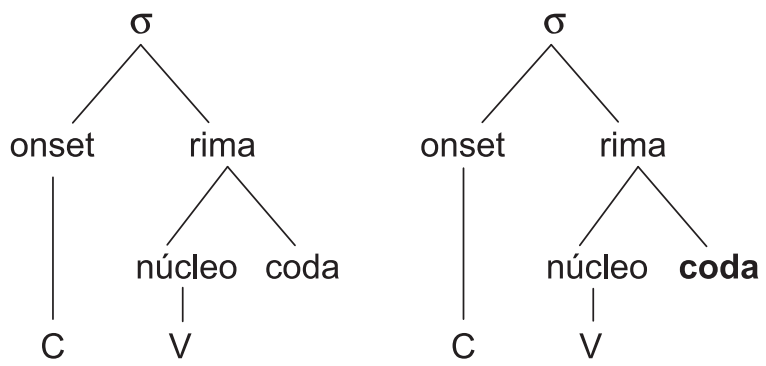
8. "banana"
['nõnǎ]
$\mathrm{CVCV}$
9. "água"
['awǎ $]^{2}$
VCV
10. "caca"
['kakǎ]
CVCV
11. "Cacá"
[kă ka]
nome para Marco
CVCV
criado por ele

12. "pomba"

['põbǎ]

CVCV

13."vovó"

[vo'vo]

CVCV 


\begin{tabular}{|c|c|}
\hline 14. "vovô" & [vo'vo] \\
\hline & $\mathrm{CVCV}$ \\
\hline 15. "nenê" & [ne'ne] \\
\hline & CVCV \\
\hline 16. "nonna" & ['nonǎ] \\
\hline & CVCV \\
\hline 17. "bola" & [’bolǎ] \\
\hline & CVCV \\
\hline 18. "carro" & ['kahu] \\
\hline & $\mathrm{CVCV}$ \\
\hline 19. "Fátima" & ['tatǎ] \\
\hline nome que ele deu & $\mathrm{CVCV}$ \\
\hline 20. "coco" & ['kokv] \\
\hline & CVCV \\
\hline 21. "cocó" & [ko'ko] \\
\hline & $\mathrm{CVCV}$ \\
\hline 22. Pitusko" & ['tukv] \\
\hline nome do gato & CVCV \\
\hline 23. "vaca" & ['vakǎ] \\
\hline & $\mathrm{CVCV}$ \\
\hline
\end{tabular}

Todos esses exemplos mostram que são estas palavras e aproximações de palavras convencionais que mais chamaram a atenção de Daniel em seu contexto. Isto não significa que outras não ocorreram neste contexto, mas as que verbalizou foram as apresentadas em ordem cronológica neste trabalho e com as que mais teve contato. 
d) Estrutura 4
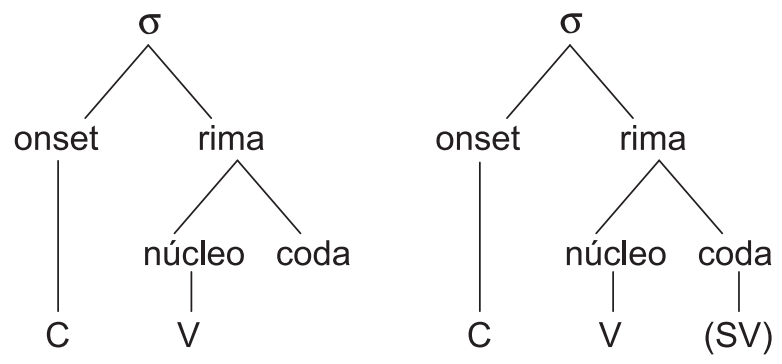

\section{(iii) Padrão CV-CVSV}
24. "papai"
[pă'pay]
CVCVSV
25. "mamãe"
[mว̌'mãy]
CVCVSV

Os exemplos a seguir mostram as aproximações que Daniel faz das palavras usadas por ele e apontam aspectos fonéticos e semânticos significativos. Alguns são apresentados contextualizadamente.

As próximas duas palavras estão inter-relacionadas foneticamente. Suas versões, ou incursões, mostram seu trabalho com a língua.
26. "titio"
[tǐ́tey]
CVCVSV
27. "piu"
['pey]
CVSV

Fonotaticamente, as combinações que aparecem até o momento da enunciação dessas palavras em coda são [ay] e [ãy], como em "papai", "ai" e "mamãe". A hipótese plausível a ser levantada é a de que os traços de [i] e [u], ambos +altos, mas distantes no que diz respeito à localização no aparelho vocal, +anterior e +posterior, respectivamente, 
não permitem a sua combinação neste estágio da fala de Daniel. Outra possibilidade seria a do final "ei" em analogia a verbos como sentei, falei, mas menos plausível do que a hipótese anterior.

As duas próximas palavras mostram uma configuração em que a combinação possível [ey] é usada para distinguir significado:

$$
\begin{array}{ll}
\text { 28. "abre" } & \text { ['abǐl] } \\
\text { 29. "abriu" } & \text { [ă } \text { '́bey] }
\end{array}
$$

A palavra "abre" ['abǐ] é usada para significar que ele quer abrir, está abrindo ou quer que alguém abra alguma coisa e [ă’bey] para significar que acabou de abrir aquela mesma coisa. É importante observar que "abrir" vem funcionando como um verbo "curinga" para Daniel, pois tem sido usado por ele em outras situações em que seu significado seria outro, o que expressa um espalhamento semântico. Vejamos os exemplos:

30. Daniel brinca com objetos que estão sobre uma mesinha. $\mathrm{Na}$ fase de colocar tudo na boca, pega uma pedrinha decorativa e a põe na boca. O pai de Daniel diz-lhe para tirar a pedra da boca.

Pai: Daniel! Tira isso da boca!!!

Pai:Daniel! Você vai engasgar!!!

Pai: Daniel! Já disse pra você que não pode pôr isso na boca!!!

Pai: Daniel! Tira isso da boca! Já!!! (em tom cada vez mais peremptório).

Daniel "finge" que não entende, pois cada vez que faz isso é alertado para o perigo.

Sem sucesso, depois de várias tentativas dizendo as mesmas coisas, o pai pega a pedra e a coloca escondida atrás de um vaso perto da cadeira onde está sentado. Daniel vai atrás da pedra. O pai coloca a perna estendida para impedi-lo de passar. Ele então diz várias vezes:

$$
\begin{array}{r}
\text { D: "Abi” "Abi" “Abi" } \\
\text { "Abi" "Abi" "Abi" }
\end{array}
$$


Sem sucesso, passa por baixo da perna do pai e vai tentar pegar a pedrinha.

31. A avó está brincando com Daniel na cozinha. Ele vai pegando os ímãs da geladeira, mostra-os (aponta-os) à avó e ela vai dizendo os nomes (minha hipótese é a de que ele mostra os objetos para a avó, esperando que ela lhe diga os nomes; de fato, o ato de apontar tem sido visto como um aspecto fundamental no processo de aquisição de uma língua, uma estratégia da criança para adquirir o léxico de sua língua). Em seguida, dirige-se ao carrinho de frutas e pega um pacotinho de orégano que está aberto. O orégano cai no chão, nos pés dele, e o incomoda. Ele está usando uma sandália aberta. Anda em direção à avó, senta-se em seu colo, mostra a sandália e diz:

D: "Abi" "Abi" "Abi"

Avó: "É pra tirar a sandália?"

Ele aponta a sandália mais uma vez.

D: "Abi" "Abi" "Abi"

Avó: "Quer tirar a sandália?"

D: "Abi" "Abi"

A avó tira a sandália e ele vai brincar com outra coisa.

Ainda com "Abi” veja o exemplo:

32. A mãe morde o pezinho de Daniel. No começo da brincadeira, ele ri muito. Depois de várias "mordidas" da mãe (creio que cansado de tanto rir), diz:

D: "Abi” "Abi" “Abi”

Um outro exemplo significativo é descrito a seguir:

33. Sempre que Daniel vai à casa da avó, ela lhe mostra um passarinho de madeira. Então, um jogo, uma brincadeira dialógica, começa entre os dois (isto a partir de dezembro; Daniel tem 1 ano e 4 meses):

Avó: "Piu"

D. "Pei" 
Avó: "Piu"

D: "Pei"

Avó: "Piu"

D: "Pei"

Após fazer esse jogo várias vezes em outras visitas, em 22/2/ 2007, a avó pega o passarinho de madeira e diz a Daniel (1 ano, 6 meses e alguns dias):

\section{Avó: "Piu"}

Daniel não responde. A avó fala "piu" várias vezes. Ele olha atentamente o passarinho. Mais uma vez a avó diz:

Avó: "Piu"

D: "Pomba"

Avó: "Piu"

D: "Pomba"

E o jogo/brincadeira se estende por vários minutos. A avó dizendo "piu" e Daniel, "pomba". Essa descrição mostra que Daniel está relacionando o som que a avó faz com a pomba, o pássaro-bicho, que vê e chama em seu quintal neste período de 2 meses, com o passarinho de madeira que a avó lhe mostra, ou seja, o pássaro-objeto. Portanto, simbolizando uma coisa pela outra, uma elaboração semântica cognitiva de alta significância, o pensamento simbólico (VYGOTSKY, 1962).

O próximo exemplo é bastante curioso e aconteceu antes destes dois últimos episódios, em dezembro de 2006, quando Daniel tinha 1 ano e 4 meses.

34. Daniel vai à casa da avó. Antes de ele sair, a avó fica falando para ele:

Avó: Daniel, você já vai embora? A vovó vai ficar com saudade. Quando é que você vai voltar? Olha! Diga pro papai trazer você logo. Vem dormir com a vovó. Tome conta do papai. Viu? [e continua falando como se ele pudesse "realmente" entender]. 
Daniel ouve atentamente olhando para a avó e diz:

D: "ti ti ti- ti ti ti- ti ti ti-ti ti ti"

Pega na mão do pai e sai andando.

e) Estrutura 5
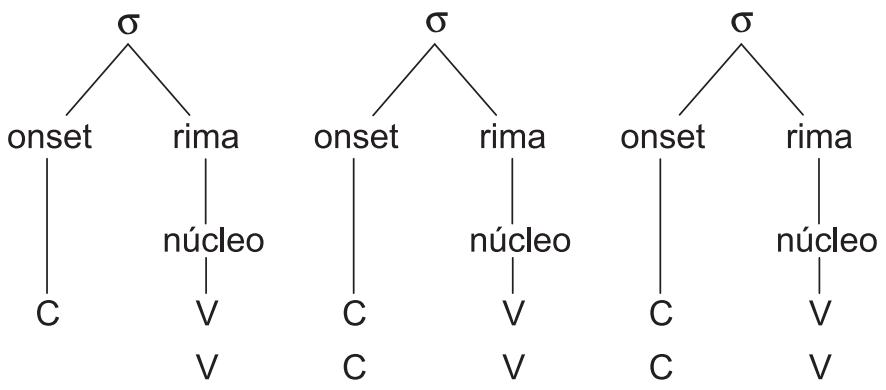

\section{(iv) Padrão CV-CV-CV/V-CV-CV}

Este padrão começa a aparecer em janeiro de 2007 (portanto, quando Daniel tinha 1 ano e 5 meses) e os exemplos são relativamente poucos. As palavras com quatro sílabas têm uma delas apagada, ou a sílaba do onset é reduplicada. A reduplicação se dá pela sílaba acentuada seguinte e também pode indicar que os adultos falam assim com ele, falar típico do baby-talk ou motherese, no caso de Daniel "ma-fa-therese" (SLobIN, 1979) ou ma-pai-terna:

35. "abóbora"

[bo’bolǎ]

CVCVCV

36. "mamadeira"

[dédelă]

CVCVCV

37. "embora"

[1'bolǎ]

de querer ir embora

VCVCV

38. "Gisele"

[zǐ́zelǐi]

CVCVCV 
f) Estrutura 6
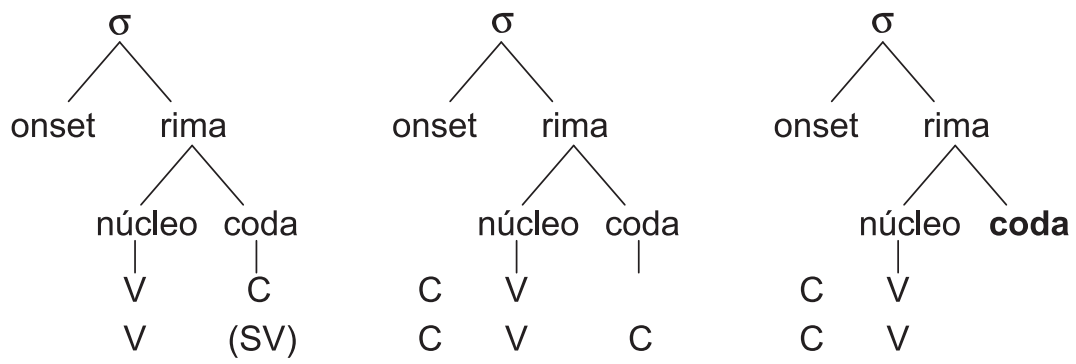

(v) Padrão VC-CV-CV/VSV-CVC-

39. "estrela"

[ǐs'telă]

VCCVCV

40. "artista"

[ay'tistǎ]

VSVCVCCV

\section{(vi) A Fonotática}

As possibilidades combinatórias silábicas da fala de Daniel até este ponto da análise mostram que:

a) as combinações com $\mathrm{V}$ somente aparecem quando seguidas por SV com as vogais [a] [ə̃] e [e]
ó [a $\{\mathrm{y}$
ó [ã $\{\mathrm{y}$
ó [ẽ $\{\mathrm{y}$

b) as combinações com consoante na coda em final de sílaba aparecem somente uma vez com [s]

ó $[\mathrm{i}\{\mathrm{s}$

c) as combinações $\mathrm{CV}$ que aparecem com as vogais:
ó $[\mathrm{m} \quad\{\mathrm{a}$ ã i
ó [n $\quad$ a ă e ã õ
ó [p \{a õ e
ó $[\mathrm{b}\}$ 


$\begin{array}{ll}\text { ó }[\mathrm{t} & \{\text { a ăa á e i u } U \\ \text { ó }[\mathrm{d} & \{\text { a e i } ~ \\ \text { ó }[\mathrm{v} & \{\text { a o } ~ \text { ă } \\ \text { ó }[\mathrm{k} & \{\text { a o } 0 \text { u } \\ \text { ó }[1 & \{\text { a i } \\ \text { ó }[\mathrm{z} & \{\varepsilon \text { i } \\ \text { ó }[\mathrm{h} & \{u\end{array}$

\section{(vii) Aproximações silábicas}

1) $[r],[y],[1]$ formam uma classe natural por terem traços distintivos compartilhados por uma classe natural, sendo, portanto, intercambiáveis e por mostrarem os mesmos processos fonológicos:

a) Final de sílaba precedida por vogal VC: $[\mathrm{r}]>[\mathrm{y}]$

b) Início de sílaba seguida por vogal CV: [r]>[1]

c) Meio de sílaba formando CCV: [ᄃ]>[ø]

2) $[\mathrm{g}]$

a) Início de sílaba funcionando como consoante: $[\mathrm{g}]>[\mathrm{w}]$. Notese que Daniel não enunciou nenhuma sílaba ou palavra com [g] até o momento.

3) Substituição do [t] pelo [d] indicando diferentes significados. Daniel não apresenta sílabas com [tš], o que indica que a africada vai aparecer depois da oclusiva em sua fala, já que faz parte da variedade de fala de sua família.

4) [uy]

a) Final de sílaba: [uy] >[ey] 


\section{(viii) Palavras (Vocábulos) Fonológicas}

Os exemplos a seguir mostram "palavras fonológicas" (MATTOsO CÂmARA, 1970) adquiridas por volta de janeiro:

O caso genitivo aparece com força e é repetido à exaustão. Até o final da coleta de dados continua a usá-lo. Aponta e/ou pega vários objetos, mostra ao interlocutor e diz:
1. "é do papai"
['Edupá pay]
2. "é da mamãe"
['Edámõ'mõy]

Após alguns dias, amplia sua concepção de genitivo, apontando o carro:

\section{3. "carro da vovó" ['kahudǎvo'vo]}

Os exemplos 1 e 2 parecem indicar que ele quer confirmar que "qualquer coisa" ou "qualquer objeto" pertence ao pai ou à mãe. Se comparados ao exemplo 3 pode-se levantar a hipótese de que "é" não está funcionando como $\mathrm{V}$ mas como $\mathrm{N}$, pois qualquer objeto pode substituir o "é" (apontando a indeterminação da raiz lexical). Como ele ainda não sabe falar o nome dos objetos, usa o "curinga", no caso, o "é". No exemplo 3, além de indicar o carro na garagem, sempre que ele quer sair para passear, ele vai até o carro e diz o mesmo ['kahudăvo'vo], ou seja, além de ser o carro da vovó (genitivo), é também um apelo para ir passear, carregando, portanto, um significado mais amplo do que o vocábulo em si possui.
4a. "me dá"
[mi'da]
do verbo dar
$\mathrm{CV}^{\prime} \mathrm{CV}$
4b. "te dá"
[di'da]
$\mathrm{CV}^{\prime} \mathrm{CV}$ 
Daniel usa esses dois exemplos para "pedir alguma coisa" e para "dar alguma coisa". Note-se que o elemento distintivo se estabelece entre o "mi" e o "di".

CONSIDERAÇões FINAIS: REFLETINDO SOBRE A ELABORAÇÃo DA FALA DE DANIEL

Fica evidente para esta autora que a fonologia métrica - por considerar a sílaba em um nível hierárquico (tiers) mais alto que o fonema e assumindo o acento (stress) como o núcleo mais saliente da seqüência fônica - possui uma importância fundamental nas primeiras descrições da aquisição de uma língua pela criança. Os dados coletados durante três meses para este corpus mostram que é apoiada na prosódia de sua língua que Daniel elabora os primeiros sons significativos de sua língua ma-pai-terna. Por prosódia, entendo, como na música, os sons altos, baixos, médios, as diferentes claves que se harmonizam (ou não, como nas composições dissonantes mais recentes) se combinam para formar um tecido musical (NeTrovsky, 2000). É óbvio que a fonética acústica é de grande utilidade nesta fase de aquisição. Contudo, restringimo-nos à fonologia métrica por acreditar que ela é um passo inicial no processo de aquisição de uma língua pela criança. Se a criança não produz sons isolados, naturalmente o segmento fônico a ser foco de análise é a sílaba, já que, como fica demonstrado neste artigo, ela é a primeira manifestação verbal significativa da criança. Como vimos, Daniel em suas primeiras incursões no mundo da fala apóia-se na sílaba acentuada, para ir gradativamente adicionando outros segmentos silábicos, onset e coda, às palavras que elabora (enquanto ainda estou escrevendo esse texto ele começou a falar "batata"; fala silabando ['ba 'ta 'ta] e, a cada sílaba, levanta e abaixa os braços). Um dos aspectos observados é a reduplicação da sílaba acentuada. Afirmar que ele faz isso somente porque ouve essas formas ao seu redor, seria ignorar que as palavras que ele constrói não possuem uma dimensão cognitiva intrinsecamente relacionada aos sons 
de uma língua (universais lingüísticos), que ele atualiza através dos sons significativos de sua língua (parâmetros) graças ao órgão ou faculdade de linguagem e das interações, eventos de fala dos quais participa. Dessa forma, acredito que as abordagens exploradas neste artigo mostram fatores decisivos na aquisição de uma língua pela criança. Em síntese, a prosódia, como afirmei anteriormente, mostra-se como um fator preponderante na aquisição de uma língua e, óbvio, na sua interface com a semântica e com a língua do corpo. Pelo que pude observar, a entoação aparece juntamente com os sons e com as expressões corporais e, neste momento, é plena de significado/função, para distinguir se a criança apenas aponta, ou pede, ou reclama, ou pergunta, enfim, para se fazer compreendida e atendida (HALLIDAY, 1969). Uma outra hipótese a ser levantada é a de que N e V são, no início do processo de aquisição, categorias maiores. Este aspecto tem sido tratado por alguns lingüistas, que colocam os demais componentes de uma língua relacionados, isto é, como "satélites" das categorias N e V (Givón, 1995). Portanto, de meu ponto de vista, mesmo sabendo que este estudo é limitado em relação ao que se tem hoje como teorias explicativas do processo de aquisição na fonética acústica, considero-o relevante para futuros estudos que possam tomá-lo como um passo significativo na compreensão do processo de aquisição de língua pela criança em seu ambiente, de sua primeira língua, sua língua ma-pai-terna.

DANIEL'S DIARY: SOME REFLECTIONS ON HIS MOTHER-FATHER LANGUAGE ACQUISITION

\section{AbStract}

Psycholinguistics is a relatively new area of Linguistics. Their main studies appeared around 1960 and have caught the interest of linguists from different theoretical approaches. This article presents a description and analysis of the first significant sounds of a child in the process of acquiring his first language. The data were collected out of speech events in his environment, comprehending the period from 1 year and three months old to 1 year and six months old, beginning December of 2006 and ending February 2007. They 
seem to give support to my hypothesis, i.e., that at this period of acquisition, the child perceives the stressed syllable as the most salient aspect of the prosody of his language. Accordingly, the metrical phonology is used to analyze the data.

KEY WORDS: psycholinguistics, language acquisition, metrical phonology.

Notas

1 Quando em final de sílaba ou de palavra o "i" e o "u" são tratados como semivogais, são grafados " $y$ " e "w", respectivamente. Ocupando locais de consoante, o "w"indica consoante aproximante.

2 A palavra "água" será tratada na fonotática. Ela foi apontada por ter aparecido cronologicamente.

\section{REFERÊNCIAS}

AgAR, M. The professional stranger: an introduction to ethnography. NewYork: Academic Press, 1980.

Berstein, B. Social class, language and socialization. In: Giglioli, P. P. (Ed.). Language and social context. London: Penguin Books, 1972.

Bloomfield, L. Language. New York: Henry Holt, 1933.

Braggio, S. L. B. Leitura e alfabetização. Da concepção mecanicista à sociopsicolingüística. Porto Alegre: Artes Médicas, 1992. (reimpresso em 2001 e 2003).

Сномsкy, N. Syntactic structures. Haia: Mouton, 1957. . Review of B. F. Skinner's Verbal Behavior. Language, n. 35, 1959. . Aspects of a theory of syntax. Cambridge: MIT Press, 1965. . Lectures on government and binding. Dortrecht: Foris, 1981.

Сномsкy, N. \& Halle, M. The sound patterns of English. New York: Harper \& Row, 1968.

CRYstal, D. The Cambridge Encyclopedia of Language. Cambridge: Cambridge University Press, 1997. 
Alves, C. Princípios, parâmetros e aquisição da linguagem. Cadernos de Estudos Lingüísticos, n. 29, 1995.

GinzBurg, C. Mitos, emblemas, sinais. São Paulo: Companhia das Letras, 1990.

Gıvón, T. Functionalism and grammar. Amsterdam: John Benjamins Publishing Company, 1995.

Goldsmith, J. Autosegmental and Metrical Phonology. Cambridge: Blackwell, 1990.

Halliday, M. A. K. Language in a social perspective. Artigo apresentado para a Sociedade Lingüística da Universidade de Oxford, Oxford, 1969.

Hyams, N. Language acquisition and the theory of parameters. Dordrecht: Reidel Publishing Co, 1986.

Hymes, D. Foundations in sociolinguistics. Pennsylvania: The University of Pennsylvania Press, 1974.

. On communicative competence. In: HuXley, R. e Ingran, E. (Eds.). Mechanisms of language development. London: University of London Press, 1967.

JAKobSon, R. Fonema e fonologia. Rio de Janeiro: Livraria Acadêmica, 1972.

Lemos, C. Sobre a aquisição da linguagem e seu dilema (pecado) original. Boletim da Abralin, v. 3, 1984. p. 97-136.

Mattoso Câmara, J. Jr. Estrutura da Língua Portuguesa. Rio de Janeiro: Vozes, 1970 .

Netrovski, A. Notas musicais. Do barroco ao Jazz. São Paulo: Publifolha, 2000.

O'Grady, William et al. Contemporary Linguistics. Boston: Bedford/St.Martins, 1997.

Perroni, M. C. Sobre o conceito de estágio em aquisição da linguagem. Cadernos de Estudos Lingüísticos, 1994.

Piaget, J. A formação do símbolo na criança: imitação, jogo, e sonho, imagem e representação. Rio de Janeiro: Zahar, 1978.

Scarpa, E. Aquisição da linguagem. In: Mussalim, F.; Bentes, A. C. (Orgs.). Introdução à Lingüística. São Paulo: Cortez Editora, 2001.

SCARPA, E. (Gebara, E.). The development of intonation and dialogue processes in two Brazilian children. 1984. Tese (Doutorado) - University of London, Londres, 1984. 
Skinner, B. F. Verbal behavior. New York: Appleton-Century Crofts, 1957.

Slobin, D. I. Psycholinguistics. Glenview: Scott, Foresman \& Company, 1979.

VyGotsky, L. S. Thought and language. Cambridge: Harvard University Press, 1962. 